\title{
Functionalizable coaxial PLLA/PDLA nanofibers with stereocomplexes at the internal interface
}

\author{
Axel T. Neffe ${ }^{1} \mathbb{D}$, Quanchao Zhang ${ }^{1}$, Paul J. Hommes-Schattmann ${ }^{1}$, Weiwei Wang ${ }^{1}$, Xun Xu1 ${ }^{1}$, \\ Bilal S. Ahmad ${ }^{2}$, Gareth R. Williams² $\odot$, Andreas Lendlein ${ }^{1, a)} \oplus$ \\ ${ }^{1}$ Institute of Active Polymers, Helmholtz-Zentrum Hereon, Teltow, Germany \\ ${ }^{2}$ UCL School of Pharmacy, University College London, 29-39 Brunswick Square, London WC1N 1AX, UK \\ a) Address all correspondence to this author. e-mail: andreas.lendlein@hereon.de \\ Received: 24 March 2021; accepted: 24 May 2021; published online: 6 July 2021
}

\begin{abstract}
Multifunctionality of electrospun polylactic acid (PLA) nonwovens was generated by the morphological design of nanofibers. Coaxial fibers with a lower number average molar mass $M_{n}$ PLLA core and a higher $M_{n}$ PDLA shell form PDLA-PLLA stereocrystals at the interface, induced by annealing. In tensile tests under physiological conditions, the core-shell fibers with higher crystallinity ( $22 \%$ compared to $11-14 \%)$ had lower Young's moduli $E(9 \pm 1 \mathrm{MPa})$ and lower elongation at break $\varepsilon_{\mathrm{b}}(26 \pm 3 \%)$ than PDLA alone ( $E=31 \pm 9 \mathrm{MPa}, \varepsilon_{\mathrm{b}}=80 \pm 5 \%$ ), which can be attributed to simultaneous crystallization and relaxation effects. Gelatin incorporated in the PDLA phase was presented on the outer surface providing a biointerface putatively favorable for cell adherence. Gelatin incorporation did not influence the crystallization behavior but slightly lowered $T_{\mathrm{g}}\left(60 \rightarrow 54^{\circ} \mathrm{C}\right)$. Employing exclusively polymers established in the clinic, multifunctionality was generated by design.
\end{abstract}

\section{Introduction}

Electrospun nonwovens have attracted interest in different fields where materials with high surface area combined with defined porosities are of interest, including membrane separation [1], in which adsorption as well as transport of liquids [2] and gasses [3] play a role, and biomedical implants, where cell adhesion and migration support a treatment $[4,5]$. Fields of envisioned biomedical application span different areas such as blood vessel grafts [6], drug release systems [7], and skin regeneration [8].

In biomaterials, the mechanical properties of a polymer play a pivotal role in the adhesion of cells and guiding cell behavior $[9,10]$ as well as for handling and responding to stresses at the site of action [11], and hence define the structural function of the material. The structural function of an electrospun mesh, including active mechanical behavior, can be adjusted by various geometrical design parameters related to different hierarchical levels, such as fiber diameter [12], fiber orientation [13, 14], interfiber interactions [15] and bonding [16] as well as material density [17] and pore size [18]. While the structural function is necessary, it alone is not sufficient for a successful biomaterial. Biofunctionalization of a polymer, i.e., providing specific sites of adhesion for cells, is a further key aspect in biomaterial design. This means that promising biomaterials are understood to beneficially display multifunctionality. Implementing such multifunctionality by the design of a material system is therefore the main task of biomaterial science. The use of clinically established compounds in this context is highly beneficial for a potential translation into the clinic.

Synthetic polymers that are used in biomaterials often belong to the family of aliphatic polyesters such as polylactide (PLA), polyglycolide, poly( $\varepsilon$-caprolactone), poly( $p$-dioxanone) and copolymers thereof [19]. The reason for their successful use is the combination of degradability, easy accessibility in medical grade, demonstrated biocompatibility in many different applications, tailorable properties, and processability by a wide variety of methods. The choice of polymer plays a key role in the mechanical properties of the fibers.

Lactide, the repeating unit of PLA, can occur in the two enantiomeric D or L forms, and PLA can hence be isotactic in the L (PLLA) or D form (PDLA), or be formed by mixtures of the two enantiomers in different ratios (PDLLA). PLA bulk mechanical properties are heavily depending on the ratio of the enantiomeric repeating units and the sequence structure, with, e.g., random PDLLA with a 1:1 ratio of $\mathrm{D}$ and L lactide being 
completely amorphous [20]. The rate of isotactic crystallization of PLA is in any case often quite slow [21]. Interestingly, the two isotactic polymers PLLA and PDLA crystallize together in socalled stereocomplexes (SC), which show a higher rate of crystallization as well as higher thermal transitions [22], mechanical stability [23] and hydrolytic resistance [24] than the isotactic crystals (homocrystallites, HC). Blends of PLLA-PDLA have been investigated in electrospinning [25-27] and also as composites [28-30]. These blends were shown to have higher Young's moduli $E$, lower elongation at break $\varepsilon_{\mathrm{b}}$, higher crystallinities, and higher melting temperatures than their isotactic analogs. SC and $\mathrm{HC}$ crystal growth in nanofibers is not independent, but rather SC are formed faster and act on the one hand as nucleation points for $\mathrm{HC}$, but on the other hand show confinement effects that may delay HC formation and guide changes in structure [31]. SC formation in fibers is furthermore facilitated through pre-ordering of polymer chains during the electrospinning process [32], but requires annealing in any case.

Here, we propose a core-shell morphology as a design parameter to impart multiple functions on PLA fiber materials. We hypothesize that stereocomplexes can only form at the interface of a layered system with one PLLA and one PDLA layer (Fig. 1) [33].

Core-shell nanofibers shall be created by electrospinning (Fig. 1B) and the obtained mesh switched from amorphous to semi-crystalline through annealing, simultaneously influencing the matrix mechanical properties. In this way, spatial control over the localization of the SC crystallites can be obtained: the stereocomplex can only be formed at the interface between core and shell. By employing a lower number average molar mass $M_{\mathrm{n}}$ PLLA core and higher $M_{\mathrm{n}}$ PDLA shell, the higher chain flexibility of the core can be exploited so that stereocomplex formation above glass transition temperatures $T_{\mathrm{g}}$ is kinetically faster than for a high $M_{\mathrm{n}}$ PLLA [34]. The stereocomplexes provide stable physical crosslinking of core and shell phases. Such interconnection of the phases would be quite different to conventional core-shell materials, which rely on some phase mixing at the interface. The envisioned structure is also different from, e.g., coaxial electrospun fibers with a crystallizable PLLA core and an amorphous PDLLA shell [35], where crystallization takes place in the inner part only: here crystallization is envisioned to take place predominantly at approximately half the radius of the fiber. The higher $M_{\mathrm{n}}$ of the shell guarantees a high elastic deformability. By stereocomplex formation, the network density is increased, which should result in a higher Young's modulus, a lower elongation at break, and putatively a higher $T_{\mathrm{g}}$. It should be noted, however, that relaxation effects, i.e., coiling of polymer chains upon heating from the electrospinning-induced extended chain conformation, may counteract such a straightforward relationship. Beyond mechanical properties, PDLA is more resistant to cleavage by enzymes present in the physiological environment compared to PLLA, which should lead to longer stability in vivo than when using PLLA or PDLLA.

Like all synthetic polymers, aliphatic esters do not offer specific sides for cell adhesion. Cell settling and migration is positively influenced by the presence of such adhesion sites, e.g.,

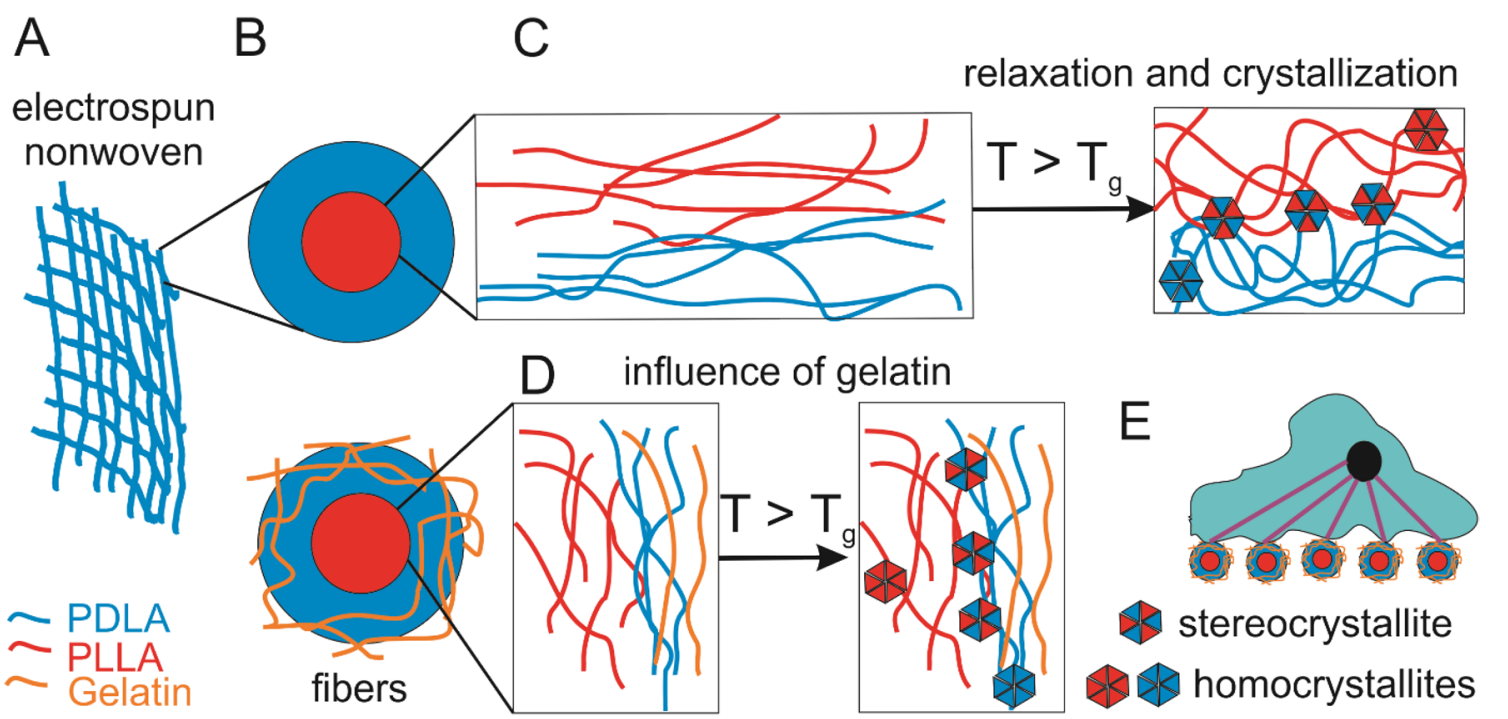

Figure 1: An application of an electrospun nonwoven $(A)$ as a biomaterial requires multifunctionality, such as appropriate structural function and cellmaterial interactions supported by biofunctionalization. (B) Core-shell structure of individual fibers with a PLLA core and a PDLA (top) or PDLA/gelatin blend (bottom) shell. (C) Chains at the interface between core and shell. Annealing the nonwoven at above glass transitions temperature allows chain relaxation and crystallization of the polymer phases. At the interface, PLLA/PDLA stereocrystallites are formed. (D) When using a PDLA/gelatin blend as the shell, gelatin may influence crystallization and mechanical properties. (E) The biofunctionalization of the fibers by gelatin incorporation putatively enables specific cell-material interactions. 
by peptides with the RGD sequence [36] or biopolymers like gelatin [37] containing such sequences. These cell adhesion sites can principally be incorporated in electrospun fibers by covalent attachment [38] or by co-electrospinning. Covalent attachment of gelatin to PLA would require introduction of suitable reactive groups [39], while the envisioned core-shell nanofibers would principally also be possible when employing a mixture of PDLA and gelatin for the shell. Addition of gelatin to PLA is known to improve cell growth [40] and has been associated with lowering of $T_{\mathrm{g}}$ compared to PLA alone [41]. In view of a later application, the incorporated biopolymer should not be physically extractable, e.g., with a good solvent (such as water), under physiological conditions. If this goal is reached, the formed polymer morphology can be interpreted as a semi-interpenetrating network with physical netpoints (crystallites). Especially when biopolymers are added, the surface properties of fibers will change also physically [40] and $T_{\mathrm{g}}$ is likely to be reduced through increased water uptake into the matrix mediated by the hydrophilic biopolymers. It is therefore of interest to show whether the above specified strategy of localizing nucleation sites for crystallization within a polymer matrix can be combined with surface functionalization, and whether such surface functionalization has an influence on the properties of the matrix.

In the following, we first show the generation of coaxial PLLA-PDLA core-shell nanofibrous patches, exploring the externally controlled ability of forming stereocomplexes by differential scanning calorimetry (DSC) and wide-angle X-ray scattering (WAXS), studying furthermore the mechanical properties under ambient conditions and in the presence of water at $37^{\circ} \mathrm{C}$ by tensile tests, and the thermal stability by thermogravimetry. In a second step, incorporation of gelatin in the shell by coelectrospinning is demonstrated. Gelatin quantification was performed by energy-dispersive X-ray spectroscopy (EDX), while the presence of gelatin on the surface is shown by coupling with fluorescein. Influence of gelatin on the crystallization, thermal transitions, and storage modulus is shown by DSC and dynamic mechanical thermal analysis at varied temperature (DMTA).

\section{Results and discussion}

The first step in the exploration of stereocomplex formation at the interface between the core and shell was the generation of fibers. Stereocomplex formation is facilitated when one of the isotactic PLAs engaging in the stereocomplex has a much lower molar mass than the corresponding partner [34], as the smaller partner has a higher mobility so that the stereocomplexes can form faster. In the envisioned core-shell structure, the question arises whether the shell or the core component should be of lower molar mass, and how that fits with the fact that polymers with large weight average molar mass $M_{\mathrm{w}}$ are required in the electrospinning process to get good continuous fibers, which is based on the entanglement of polymer chains. These seemingly contradictory requirements were addressed using a high $M_{\mathrm{w}}$ PDLA for the shell and for the core PLLA phase a blend of a relatively low $M_{\mathrm{w}}=27 \mathrm{~kg} \cdot \mathrm{mol}^{-1}$ polymer with a PLLA of high $M_{\mathrm{w}}=145 \mathrm{~kg} \cdot \mathrm{mol}^{-1}(5: 1 \mathrm{w} / \mathrm{w})$. As is known for, e.g., copper or glass fiber cables, an elastic outer shell can protect a more brittle inner part, and hence the higher $M_{\mathrm{w}}$ PDLA was used as the shell, while PLLA was used as core.

The electrospinning was performed with $5 \mathrm{wt} \%$ PDLA in hexafluoroisopropanol (HFIP) for the shell, while the core solution contained $12 \mathrm{wt} \%$ of the PLLA mixture. In addition, nonwovens of PDLA and PLLA alone were produced in the same way. The electrospun nonwovens were analyzed by electron microscopy, giving information about fiber orientation and diameter (Fig. 2). In all cases, random orientated fibers were generated. A TEM image visualizes the core-shell structure of the PLLA/PDLA fibers. Such structures with relatively clear boundary between core and shell have been observed also in other cases of core/shell fibers with core and shell materials with similar chemical composition [42], and it could be argued that the contrast is enhanced by stereocrystallites on the border between the two phases. However, it has to be considered that the greater thickness in the middle of the fibers will result in greater contrast in any case, though in monolithic fibers this typically manifests as a gradual change in color without a clear boundary.

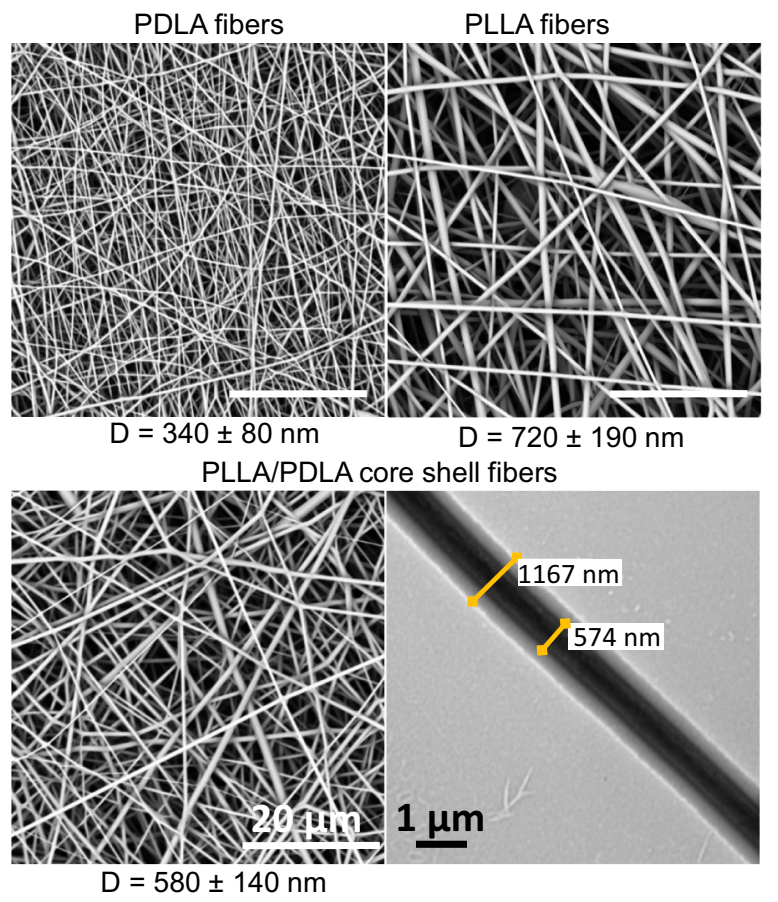

Figure 2: SEM images of PDLA (top left), PLLA (top right), and PLLA/PDLA core-shell fibers (bottom left). TEM image of a PLLA/PDLA core-shell fiber (bottom right). 
As it is known that annealing is typically required for the homo- and stereocrystallization of PLA in nanofibers [43], the thermal transitions, structural function, and crystallinity of as-spun and annealed nonwovens were investigated in comparison to explore the switching from an amorphous to a semi-crystalline material and show the changes in mechanical properties. The thermal transitions and crystallinities of the as-spun and of annealed fibers (Fig. 3, Table 1 and Supporting Information (SI) Figure S1) were studied by DSC. For the asspun fibers, in the first heating there was an endothermal peak
PLLA
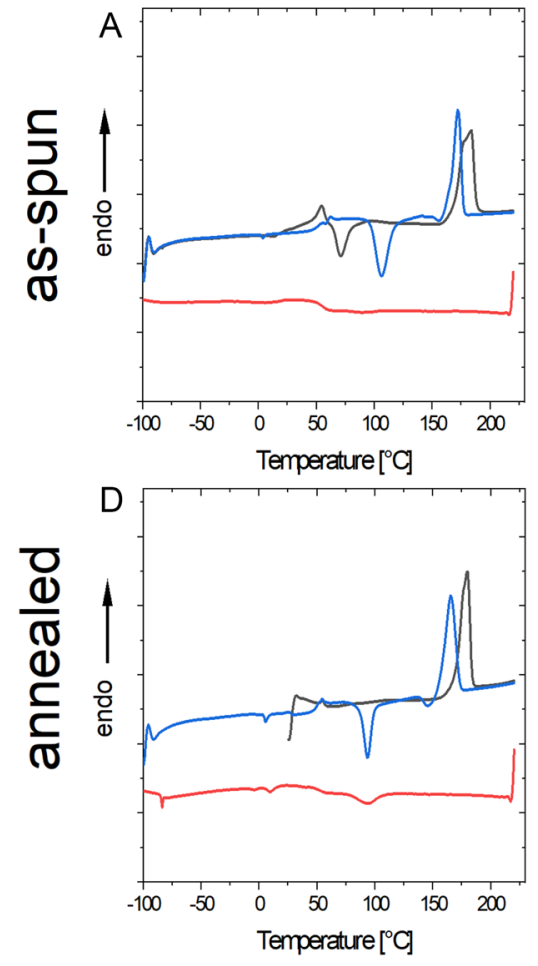

PDLA
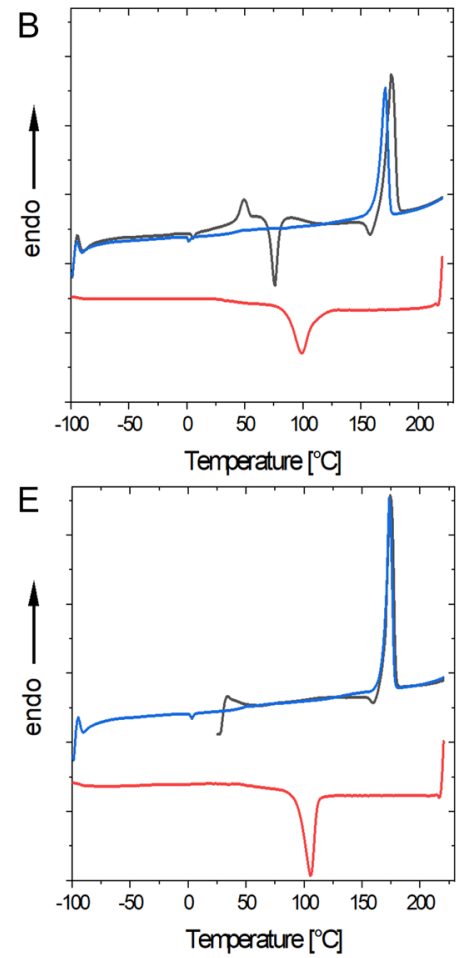

core/shell
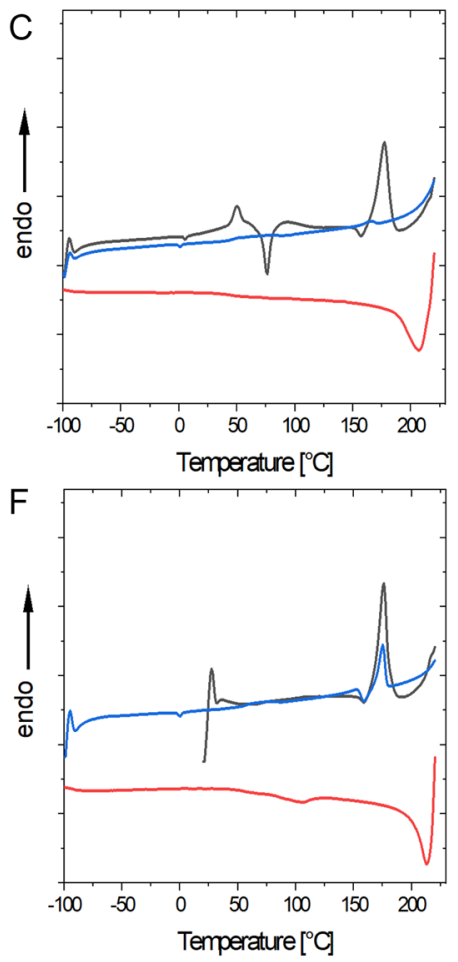

Figure 3: DSC studies of electrospun fibers. (A)-(C): as-spun $\left(-100^{\circ} \mathrm{C} \rightarrow 220^{\circ} \mathrm{C} \rightarrow-100^{\circ} \mathrm{C} \rightarrow 220^{\circ} \mathrm{C}\left[->300^{\circ} \mathrm{C}\right.\right.$ for (C), only depicted till $\left.220^{\circ} \mathrm{C}\right]$. Full curve see SI Figure S1), (D)-(F): annealed $\left(2 \mathrm{~h}, 100^{\circ} \mathrm{C}\right)\left(20^{\circ} \mathrm{C} \rightarrow 220^{\circ} \mathrm{C} \rightarrow-100^{\circ} \mathrm{C} \rightarrow 220^{\circ} \mathrm{C}\right)$. A) and D): PDLA, B) and E): PLLA. C) and F): PLLA-PDLA core-shell fibers. Black: $1^{\text {st }}$ heating run, red: cooling, blue: $2^{\text {nd }}$ heating run. Heating/cooling rate: $10^{\circ} \mathrm{C} \cdot \mathrm{min}^{-1}$.

TABLE 1: Thermal transitions, melting enthalpies, and crystallinities of as-spun and annealed fibers determined by DSC. Annealed: Nonwoven was tempered at $100^{\circ} \mathrm{C}$ for $2 \mathrm{~h}$. Heating/cooling regimes: as-spun: $\left(-100^{\circ} \mathrm{C} \rightarrow 220^{\circ} \mathrm{C} \rightarrow\right.$ $-100^{\circ} \mathrm{C} \rightarrow 220^{\circ} \mathrm{C}\left[->300^{\circ} \mathrm{C}\right.$ for core-shell fibers, only depicted till $220^{\circ} \mathrm{C}$. Full curve see SI Figure S1]), annealed $\left(20^{\circ} \mathrm{C} \rightarrow 220^{\circ} \mathrm{C} \rightarrow-100\right.$ ${ }^{\circ} \mathrm{C} \rightarrow 220^{\circ} \mathrm{C}$ ). Heating/cooling rate: $10^{\circ} \mathrm{C} \cdot \mathrm{min}^{-1}$.

\begin{tabular}{|c|c|c|c|c|c|c|c|c|c|c|}
\hline Status & Sample & $\begin{array}{l}\mathrm{T}_{\mathrm{m}}^{1 \text { st }} \\
{\left[{ }^{\circ} \mathrm{C}\right]}\end{array}$ & $\begin{array}{c}\mathrm{T}_{\mathrm{m}}{ }^{1 \text { st }} \text { range } \\
{\left[{ }^{\circ} \mathrm{C}\right]}\end{array}$ & $\begin{array}{l}\Delta \mathrm{H}_{\mathrm{m}}^{1 \mathrm{st}} \\
{\left[\mathrm{J} \cdot \mathrm{g}^{-1}\right]}\end{array}$ & $\begin{array}{c}\mathrm{T}_{m}^{2 \text { 2nd }} \\
{\left[{ }^{\circ} \mathrm{C}\right]}\end{array}$ & $\begin{array}{c}\mathrm{T}_{\mathrm{m}}{ }^{\text {2nd }} \text { range } \\
{\left[{ }^{\circ} \mathrm{C}\right]}\end{array}$ & $\begin{array}{c}\Delta \mathrm{H}_{\mathrm{m}}^{2 \text { 2nd }} \\
{\left[\mathrm{J} \cdot \mathrm{g}^{-1}\right]}\end{array}$ & $\begin{array}{c}\mathrm{T}_{\mathrm{g}} \\
{\left[{ }^{\circ} \mathrm{C}\right]}\end{array}$ & $\begin{array}{l}\phi_{c}{ }^{1 \text { st }} \\
{[\%]}\end{array}$ & $\begin{array}{c}\phi_{c}^{2 n d} \\
{[\%]}\end{array}$ \\
\hline \multirow[t]{6}{*}{ As-spun } & PDLA & 183 & 159-193 & 51.5 & 173 & 156-179 & 38.9 & 55 & 56.0 & 41.9 \\
\hline & PLLA & 176 & $156-186$ & 57.7 & 170 & $151-180$ & 42.6 & 47 & 62.7 & 45.8 \\
\hline & Core/Shell & 177 & $157-190$ & 46.2 & 166 & $155-171$ & 1.0 & 56 & 49.7 & 1 \\
\hline & & & & & 232 & $206-239$ & 45.3 & & & 31.9 \\
\hline & & 177 & $158-191$ & 50.4 & - & - & - & n.d & 54.2 & - \\
\hline & & 225 & $201-239$ & 25.4 & - & - & - & n.d & 17.9 & - \\
\hline \multirow[t]{3}{*}{ Annealed } & PDLA & 179 & 157-189 & 50.5 & 165 & $147-178$ & 48.8 & 51 & 54.9 & 52.5 \\
\hline & PLLA & 173 & 159-182 & 38.2 & 173 & 159-182 & 50.8 & 49 & 41.5 & 54.7 \\
\hline & Core/Shell & 176 & $159-189$ & 49.1 & 175 & 159-182 & 16.4 & 58 & 53.4 & 17.7 \\
\hline
\end{tabular}

$\mathrm{T}_{\mathrm{m}}$ : melting transition temperature; $\Delta \mathrm{H}_{\mathrm{m}}$ : melting enthalpy; $\mathrm{T}_{\mathrm{g}}$ : glass transition temperature (determined from the second heating run); $\phi_{\mathrm{c}}{ }^{\mathrm{HC} / \mathrm{SC}}$ : absolute crystallinity of homo- and stereocrystallites; 1 st: first heating run; 2nd: second heating run. Italic lines: determined from an experiment with $300{ }^{\circ} \mathrm{C}$ as end temperature in the first heating run (see SI Figure S1). n.d.: not determinable (due to the relaxation effects). 
at $\sim 50{ }^{\circ} \mathrm{C}$, which can be attributed to strong relaxation effects, i.e., entropy elastic coiling behavior of the polymer chains extended during the electrospinning process, which occurred around $T_{\mathrm{g}}$. Due to these relaxation effects, the exact $T_{\mathrm{g}}$ cannot be determined from this heating curve. Upon further heating, the exothermal peak at $\sim 75^{\circ} \mathrm{C}$ shows that a notable percentage of the observed crystallinity was formed during the heating phase and not during the spinning/solidification. In the evaluation of the data, it should be considered that there may be some overlap of the relaxation and crystallization processes, so one should not compare the melting and crystallization enthalpies directly to quantify the amount of crystallization during the DSC experiment.

In all three sample types (PDLA, PLLA and coaxial fibers), homocrystallites could be observed (melting temperature $\mathrm{T}_{\mathrm{m}} \sim 177^{\circ} \mathrm{C}$ ), but in the coaxial fibers a second melting transition corresponding to stereocrystallites occurred in addition (above $220^{\circ} \mathrm{C}$, see SI Figure S1). It should be noted that thermal degradation of PLA samples is observed starting at about $220^{\circ} \mathrm{C}$ (compare Fig. 5B). Therefore, in experiments in which a cooling and 2 nd heating were undertaken, the upper limit in the first heat was set to $220^{\circ} \mathrm{C}$. The melting temperature and melting enthalpy of the PDLA and PLLA samples were generally a little lower in the 2nd heating run than in the first. However, in the as-spun coaxial fibers, the stereocrystallinity measured in the second heating run was higher than in the first heating run, and homocrystallinity was extremely low $(\sim 1 \%)$ in the second heating. This probably reflects the faster formation and the higher stability of stereocrystallites compared to homocrystallites.

In the annealed fibers, no crystallization or relaxation was observed in the heating process, presumably because this has occurred during the annealing, and the overall crystallinity was a little lower than in the as-spun fibers. Isothermal crystallization during the cooling phase was observed in the PLLA samples (as-spun as well as annealed) to a much stronger extent than in the core-shell fibers, while it was not observed in the PDLA fibers. This may be rationalized by the fact that the molar mass of the PLLA samples is much lower than that of the PDLA. This means that the PLLA chains have a lower $T_{\mathrm{g}}$ and a higher mobility under the experimental conditions. The $T_{\mathrm{g}} \mathrm{s}$ determined from the second heating run, which were also observable in the cooling, were as typically found for PLA $\left(\sim 50-60^{\circ} \mathrm{C}\right)$.

The influence of annealing temperature and time on the thermal transitions and crystallinity determined by DSC was investigated by annealing at $60,70,80,90,100,110$ and $120^{\circ} \mathrm{C}$ for $1 \mathrm{~h}$, or, alternatively, at $100{ }^{\circ} \mathrm{C}$ for $25,50,60,90,120,180$, $240 \mathrm{~min}$ and $36 \mathrm{~h}$ (see SI Figures S2 and S3 and SI Tables S1 and S2). There was no clear increase of crystallinity found in the annealing experiments, and also no change of relative homoand stereocrystallinity. This suggests that the crystallization is relatively fast, partially occurring during the heating in the DSC experiment, and that there is only a certain zone in the polymer fibers in which stereocrystallization can take place.

There are two main reservations to be considered when assessing stereocomplex formation by DSC. First, crystallization may change during the heating phase, so the melting transition might not adequately describe the crystal structure at room temperature. Second, while stereocrystallites can have melting transitions up to $230^{\circ} \mathrm{C}$, small crystallites can have much lower melting transitions falling in the same range, at which the melting of homocrystallites is observed [44]. Therefore, a second method to prove the presence of homo- and stereocrystals in the as-spun and the annealed fibers is required. For this purpose, wide-angle X-ray scattering (WAXS) was employed.

Figure 4 shows the WAXS results from as-spun and annealed PDLA and core-shell fibers (for PLLA fibers see SI Figure S4). The as-spun fibers appear completely amorphous, while in the annealed fibers crystallites are present. Only in the annealed core/shell fibers peaks associated with stereocomplexes $(2 \theta=$ $12^{\circ}, 21^{\circ}$ ) are occurring. Furthermore, the overall degree of crystallinity in the annealed core-shell fibers $(22 \%)$ is higher than in the annealed PDLA (11\%) or PLLA (14\%) fibers. This highlights the fact that stereocomplexes may here be regarded as points of crystallization for the otherwise slowly crystallizing isotactic PLA. This supports the understanding that the envisioned matrix morphology with crystallites being formed at the inner interface, and only upon thermal treatment, was observed in the experiments.

Comparing different annealing times at $100^{\circ} \mathrm{C}$ for the core-shell fibers, an increase in crystallinity (to 17.1\%) was observed after extended annealing ( $36 \mathrm{~h}$ ), while at shorter annealing times no clear correlation between annealing time and crystallinity (6.5-14.7\%) was observed (Fig. 4B and SI Figure S5A). Homo- as well as stereocrystallites were formed. Comparing different annealing temperatures (Fig. 4C and SI Figure $\mathrm{S} 5 \mathrm{~B})$, at $60^{\circ} \mathrm{C}$ very low crystallization (4.7\%) was observed in the core-shell fibers. This can be rationalized by the fact that $60{ }^{\circ} \mathrm{C}$ is very close to the glass transition temperature of the core-shell fibers $\left(56-58^{\circ} \mathrm{C}\right)$ and therefore the molecular mobility might be too low to observe crystallization within $1 \mathrm{~h}$. At higher temperatures, homo- and stereocrystals were formed, and no clear relation between annealing temperature and degree of crystallinity (6.6-15.8\%) was observed. It can therefore be concluded that the development of homo- and stereocrystallites in the electrospun fibers required annealing. The annealing temperature has to be significantly higher than the glass transition temperature in order to get effective crystallization.

The mechanical properties of the as-spun and annealed fibers were determined in tensile tests at room temperature, and for the annealed fibers in addition at $37^{\circ} \mathrm{C}$ in a water tank, simulating physiological conditions (Table 2 and Fig. 5). As-spun core-shell fibers had a similar Young's modulus E as PDLA, 

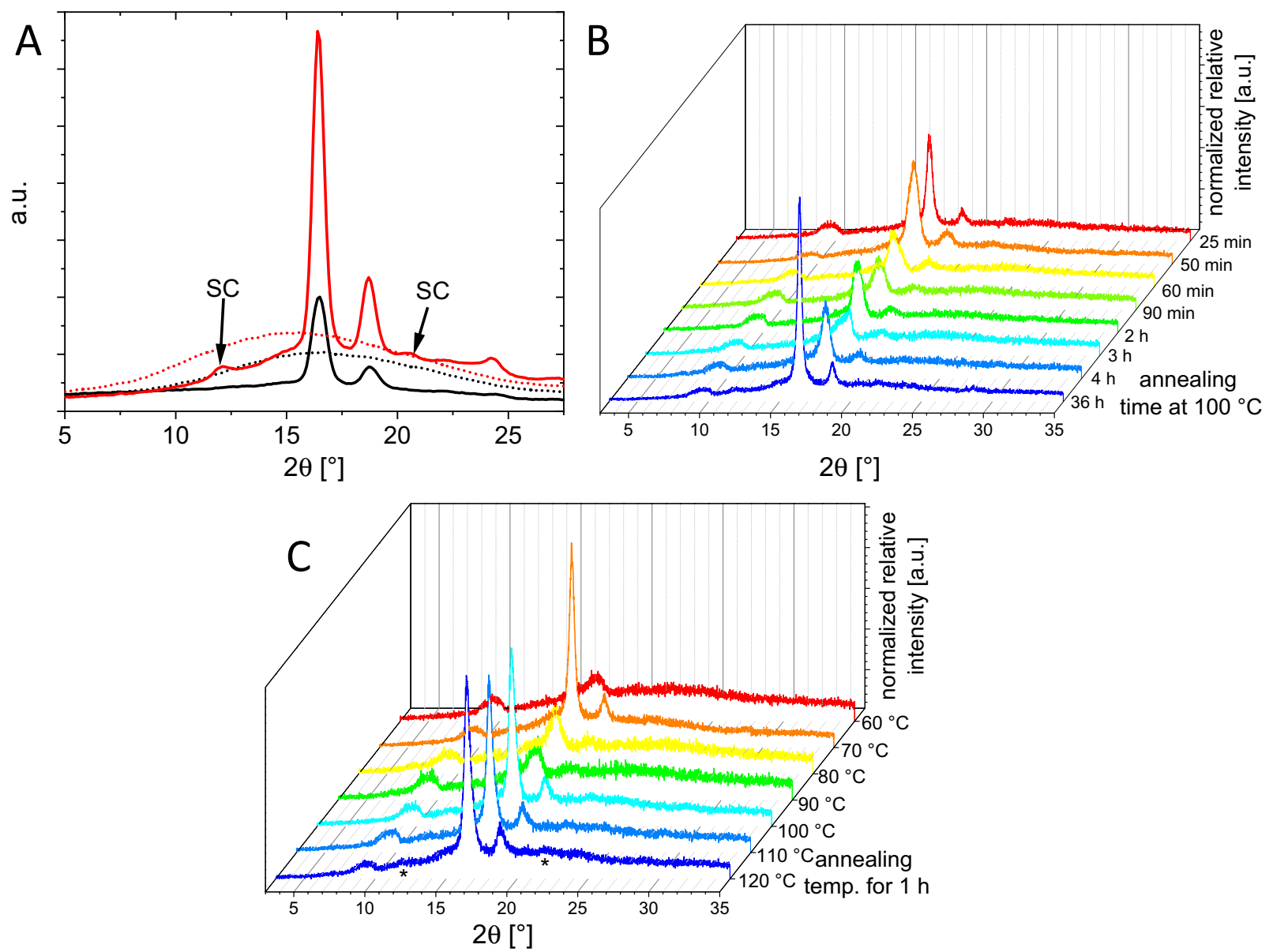

Figure 4: A) WAXS spectra of as-spun (dots) or annealed (line) PDLA (black) and core/shell (red) fibers. (B/C) Kinetics of stereocomplex formation studied by WAXS, comparing different annealing times at $100^{\circ} \mathrm{C}$ (B) or different annealing temperatures (1 h) (C).

TABLE 2: Mechanical properties of PDLA, PLLA, and core-shell fiber mats as-spun or annealed at $100{ }^{\circ} \mathrm{C}$ for $2 \mathrm{~h}$, measured at room temperature, and, for the materials measured after annealing, at $37^{\circ} \mathrm{C}$ in a water tank.

\begin{tabular}{lcrr}
\hline \hline & $\begin{array}{c}\text { Young's modulus } \\
{[\mathrm{MPa}]}\end{array}$ & $\begin{array}{c}\sigma_{\max } \\
{[\mathrm{MPa}]}\end{array}$ & \multicolumn{1}{c}{$\begin{array}{c}\varepsilon_{\mathrm{b}} \\
{[\%]}\end{array}$} \\
\hline PDLA as-spun & $47 \pm 6$ & $2.9 \pm 0.4$ & $146 \pm 14$ \\
PDLA annealed & $23 \pm 3$ & $4.5 \pm 0.1$ & $150 \pm 15$ \\
PDLA annealed, $37^{\circ} \mathrm{C}^{\mathrm{a}}$ & $31 \pm 8$ & $5 \pm 0.5$ & $80 \pm 5$ \\
PLLA as-spun & $70 \pm 33$ & $2.7 \pm 0.2$ & $32 \pm 2$ \\
PLLA annealed & $65 \pm 21$ & $2.4 \pm 0.2$ & $9 \pm 2$ \\
PLLA annealed, $37^{\circ} \mathrm{C}^{\mathrm{a}}$ & $28 \pm 13$ & $1.5 \pm 0.4$ & $8 \pm 2$ \\
Core/shell as-spun & $46 \pm 8$ & $1.9 \pm 0.2$ & $92 \pm 18$ \\
Core/shell annealed & $21 \pm 3$ & $2.5 \pm 0.01$ & $30 \pm 3$ \\
Core/shell annealed, $37^{\circ} \mathrm{C}^{\mathrm{a}}$ & $9 \pm 1$ & $3.8 \pm 0.2$ & $26 \pm 3$ \\
\hline \hline
\end{tabular}

${ }^{\mathrm{a}}$ In water.

which was lower than for the PLLA fibers. Annealing led to a reduction of $E$, though crystallinity increased with annealing, and typically $E$ increases with crystallinity [45-47]. However, another process occurring above $T_{g}$ is chain relaxation, which was also observed in the DSC studies as explained above. Relaxation is of particular relevance in electrospun polymers as the process leads to extended chains [48]. If annealing is performed under conditions that only leads to low crystallization, relaxation and crystallization together results in reduction of $E$ in the initial states of annealing [49]. The degrees of crystallinity determined by WAXS after the annealing procedure are still relatively low (11-22\%) compared to systems reported in the literature where PLLA was annealed for much longer times and partially at higher temperatures (>30\%) $[45,48]$. Nevertheless, it can be clearly stated that the fiber design allowed switching of bulk properties through spatially controlled crystallization.

Interestingly, the core-shell samples are softer than the comparable PDLA despite having higher crystallinities. $E$ furthermore tended to be lower under physiological conditions than at room temperature, likely because the measurement was made closer to the $T_{\mathrm{g}}$ of the fibers than when at room temperature. Water uptake into the fibers may furthermore have reduced $T_{\mathrm{g}}$. It should further be noted that the fiber diameters of the nonwovens are in a range in which differences 

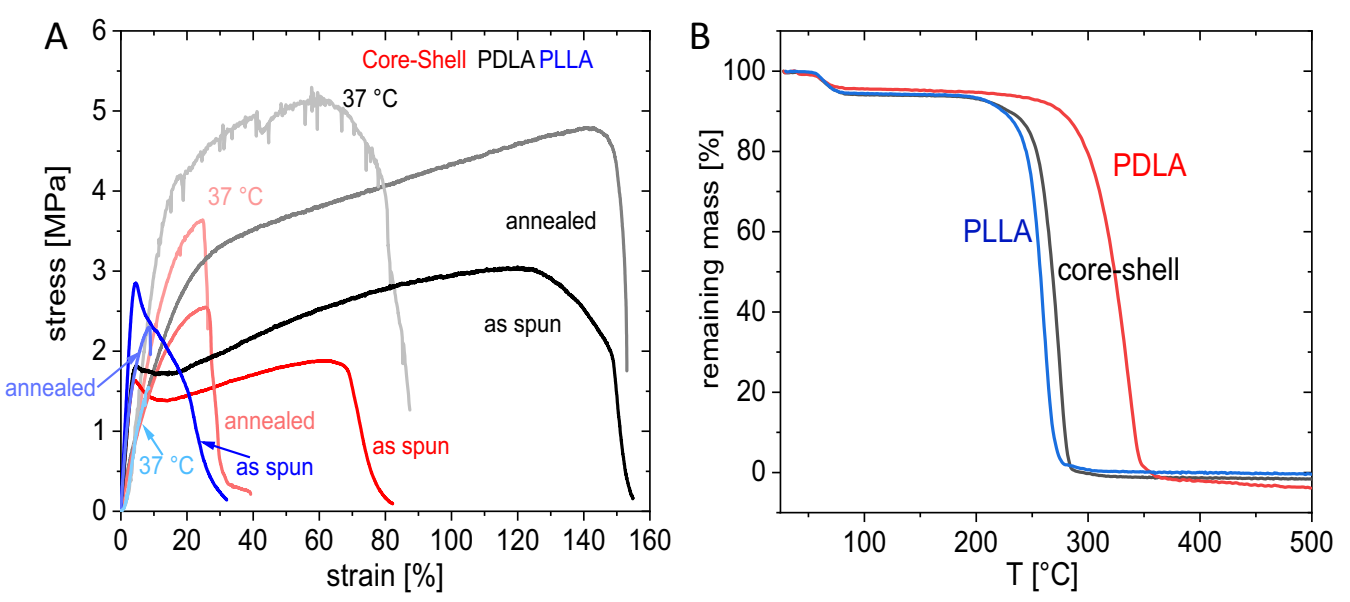

Figure 5: (A) Stress-strain curves of PDLA, PLLA, and core-shell fiber mats as-spun, annealed, and at $37^{\circ} \mathrm{C}$ in water after annealing. (B) Thermal degradation of PDLA, PLLA, and core-shell nanofibers.

in diameter may have a strong impact on Young's moduli and crystallinity [45], both of which inversely correlate with the fiber diameter. However, in the studied samples, no such clear trend was found. The elongation at break $\varepsilon_{\mathrm{b}}$ tended to be higher in the as-spun fibers than for the annealed nonwovens, and further reduced at $37^{\circ} \mathrm{C}$ compared to room temperature. At high strains, the crystalline part plays a very strong role, and the reduction of $\varepsilon_{\mathrm{b}}$ with annealing and crystallinity is well documented [46, 47]. The lower $\varepsilon_{\mathrm{b}}$ for the PLLA nonwovens compared to the other two samples can be attributed to the lower $M_{\mathrm{w}}$ and hence lower propensity for chain entanglements that would increase $\varepsilon_{\mathrm{b}}$.

The thermal degradation of the nonwovens was studied by TGA (Fig. 5B). The first small mass loss at $\sim 60^{\circ} \mathrm{C}$ can likely be attributed to residual solvent (boiling point of HFIP: $58.2^{\circ} \mathrm{C}$ ). PLLA and the core-shell nonwovens had distinctly lower degradation temperatures (50 wt\% remaining mass at 257 and $\left.268^{\circ} \mathrm{C}\right)$ than PDLA $\left(323^{\circ} \mathrm{C}\right)$. The onset of polymer degradation ( $5 \mathrm{wt} \%$ mass loss from the plateau) was likewise lower for PLLA $\left(225^{\circ} \mathrm{C}\right)$ and the core-shell structure $\left(231^{\circ} \mathrm{C}\right)$ than for PDLA $\left(275^{\circ} \mathrm{C}\right)$. As the heating rate was the same as in the DSC experiments $\left(10^{\circ} \mathrm{C} \cdot \mathrm{min}^{-1}\right)$, it can be assumed that the crystallinities of the materials are similar to those determined by DSC. The main difference between the samples was the molar mass, and it is known that the degradation temperature of PLA increases with the molar mass [50].

Summarizing the results so far, it is clear that coaxial PLA fibers have been generated. In these coaxial fibers, stereocrystallite formation can only take place at the interface, or a putatively formed interphase, and could be initiated by annealing. The Young's modulus of the annealed electrospun nonwoven, with $E$ in the lower MPa range, is fitting to the requirements of applications such as in cardiovascular tissue regeneration.
Following our design concept, in a second step we explored whether gelatin could be incorporated in the outer shell and be displayed on the surface [37], studying in addition the influence of gelatin on the crystallization as well as the stability of the gelatin incorporation. By mixing gelatin with PDLA in different ratios $(5,10,15,20$, and $30 \% \mathrm{v} / \mathrm{v}$ with respect to the PDLA solution, giving shells of nominal composition of $6.9,13.5,19.8$, 25.9 and $37.5 \mathrm{wt} \%$ gelatin), core-shell fibers were created whose shell consists of PDLA and gelatin. The produced fibers (see Fig. 6A, Table 3, and SI Figure S6) had similar dimensions for all nominal gelatin contents with fiber diameters of $\sim 550 \mathrm{~nm}$.

It was now necessary to prove that gelatin was present in the fibers, as potentially demixing might have occurred. In FTIR spectra, no signals associated with gelatin were observed (SI Figure S7), which may be because the overall gelatin content, also considering the PLLA part, is very low. Likewise, in thermogravimetry (SI Figure S8) no two-step degradation was observed, and it was not possible to attribute a certain degradation temperature to a specific component of the blend. However, all gelatin-containing samples had higher degradation temperatures ( $50 \mathrm{wt} \%$ remaining mass at $275-307^{\circ} \mathrm{C}$ ) than the core-shell nonwoven $\left(268^{\circ} \mathrm{C}\right)$.

Gelatin, in contrast to PLA, contains nitrogen and so the EDX detector in electron microscopy provided additional means to determine the gelatin content (Table 3 and Fig. 6C). All gelatin samples contained nitrogen (0.06-0.58 at\%). However, an absolute quantification was not possible, as the $\mathrm{C}, \mathrm{O}$ and $\mathrm{N}$ content was altered by carbon sputtering during sample preparation. Furthermore, quantification is only accurate at $\geq 0.5$ at $\%$. However, the N/O ratio is a useful value for estimating the gelatin content. In this way, $0.6-7.9 \mathrm{wt} \%$ overall gelatin content in the fibers could be calculated, with increasing quantified percentages of gelatin correlating with the rising nominal gelatin 
A
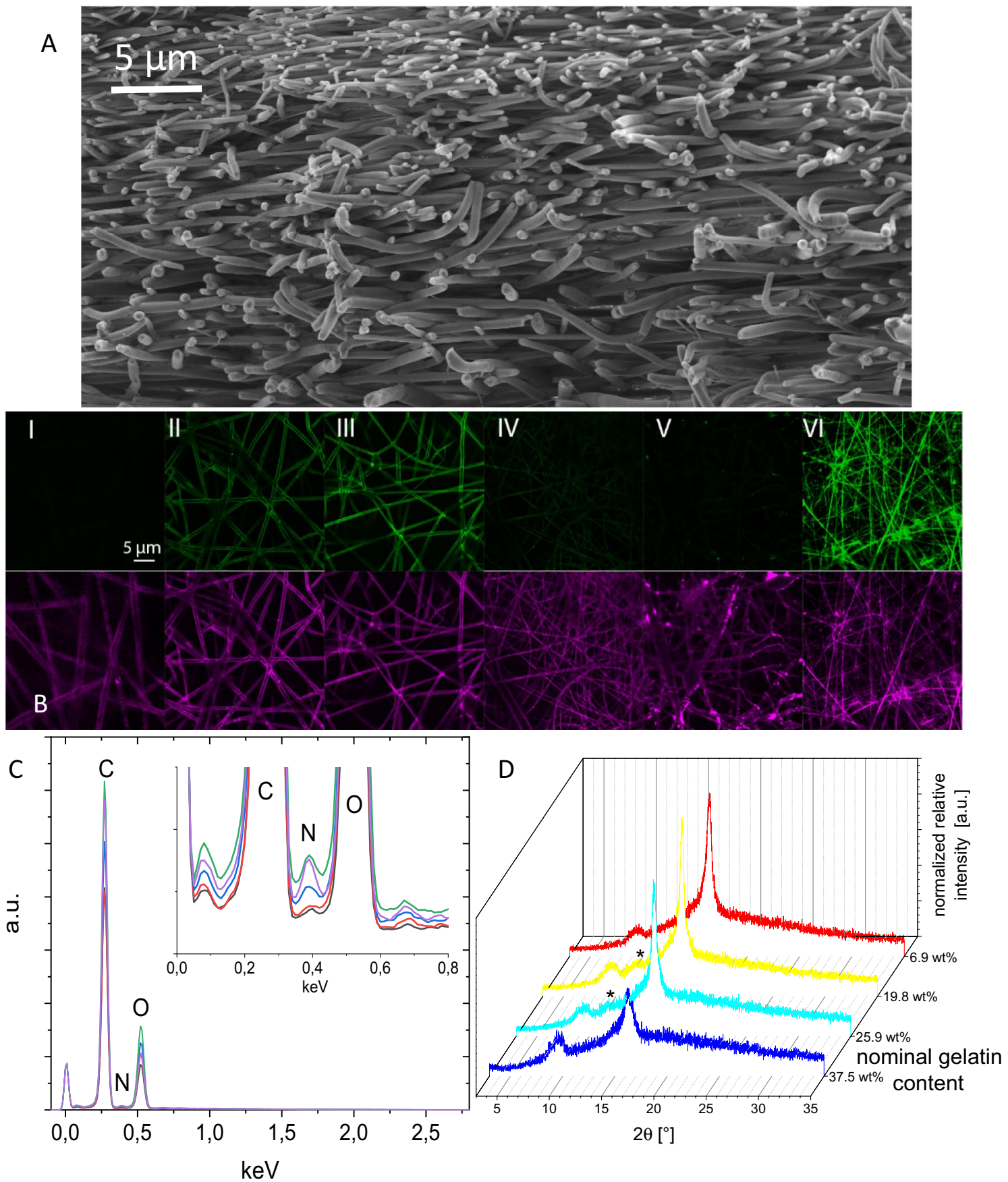

Figure 6: (A) Electron microscopy image of core-shell nanofibers (break edge) with a nominal $37.5 \mathrm{wt} \%$ gelatin content in the shell. (B) Confocal laser scanning microscopy of core-shell PLLA/PDLA nanofibers with different nominal weight content of gelatin in the shell (I: $0 \mathrm{wt} \%$, II: $6.9 \mathrm{wt} \%$, III: 13.5 wt $\%$, IV: 19.8 wt\%, V: 25.9 wt\%, VI: 37.5 wt\%). Gelatin was labeled by reacting with NHS-fluorescein. Upper row: fluorescein. Lower row: autofluorescence of nanofibers. (C) EDX spectra of core-shell nanofibers with different nominal weight contents of gelatin added in the shell. Black: 6.9 wt\%, red: $13.5 \mathrm{wt} \%$, blue: $19.8 \mathrm{wt} \%$, green: $25.9 \mathrm{wt} \%$, lilac: $37.5 \mathrm{wt} \%$. (D) Core-shell nanofibers with different gelatin contents after $30 \mathrm{~min}$ annealing at $70^{\circ} \mathrm{C}$. There are peaks showing up in the $19.8 \mathrm{wt} \%$ and $25.9 \mathrm{wt} \%$ gelatin samples marked by an * that indicate stereocomplex formation.

content. It should be noted that the gelatin content is close to or below the quantification limit of many methods, including EDX. The obtained values suggest lower gelatin content than the nominal values, though no residues (e.g., in the vials) were observed in the electrospinning process. The observed values may be underestimates of the actual percentage, as oxygen might absorb on the samples during preparation for the EDX analysis. Electron microscopy did not allow us visualizing the spatial distribution of gelatin in the fiber (attempts were made using both EDX and TEM, data not shown). 
TABLE 3: Fiber diameters determined from SEM images and $\mathrm{N} / \mathrm{O}$ ratios expected at different nominal gelatin contents in the outer layer and values determined by EDX.

\begin{tabular}{|c|c|c|c|c|c|c|}
\hline & $\begin{array}{c}\varnothing \\
{[\mathrm{nm}]}\end{array}$ & $\begin{array}{c}\mathrm{N} \text { measured } \\
\text { [wt\%] }\end{array}$ & $\begin{array}{c}\text { N/O ratio expected } \\
{[\%]}\end{array}$ & $\begin{array}{c}\text { N/O ratio measured } \\
{[\%]}\end{array}$ & $\begin{array}{c}\text { Incorporation factor } \\
{[\%]}\end{array}$ & $\begin{array}{c}\text { Gelatin content } \\
{\left[{ }^{w} \mathrm{t} \%\right]^{\mathrm{a}}}\end{array}$ \\
\hline $\begin{array}{l}\text { Core-shell, } \\
6.9 \text { wt } \% \text { Gelatin }\end{array}$ & $570 \pm 110$ & 0.11 & 1.1 & 0.6 & 58.8 & 1.4 \\
\hline $\begin{array}{l}\text { Core-shell, } \\
13.5 \text { wt\% Gelatin }\end{array}$ & $580 \pm 210$ & 0.06 & 2.2 & 0.3 & 13.8 & 0.6 \\
\hline $\begin{array}{l}\text { Core-shell, } \\
19.8 \text { wt\% Gelatin }\end{array}$ & $560 \pm 210$ & 0.22 & 3.2 & 1.1 & 34.7 & 2.3 \\
\hline $\begin{array}{l}\text { Core-shell, } \\
25.9 \text { wt } \% \text { Gelatin }\end{array}$ & $550 \pm 120$ & 0.3 & 4.2 & 1.5 & 35.7 & 3.2 \\
\hline $\begin{array}{l}\text { Core-shell, } \\
37.5 \text { wt } \% \text { Gelatin }\end{array}$ & $540 \pm 120$ & 0.58 & 6.1 & 3.7 & 61.2 & 7.9 \\
\hline
\end{tabular}

${ }^{a}$ Overall gelatin content in the fiber (core + shell $)=\frac{m_{g e l}}{m_{g e l}+m_{P L A}} \times$ incorp.factor with $m_{x}$ as nominal mass content.
The presence of gelatin on the surface of the fibers, as is required for cell adhesion, could be shown by fluorescence microscopy (Fig. 6B) [37]. For this purpose, the fibers were incubated with NHS-fluorescein. The NHS-activated carboxylic acid group of fluorescein reacts with any nucleophilic group, establishing a covalent bond. Such nucleophiles $\left(-\mathrm{NH}_{2},-\mathrm{OH}\right)$ are present in gelatin but not in PLA. Therefore, fibers containing gelatin at the surface should exhibit green fluorescence. All gelatin-containing fibers fluoresced, though not necessarily with increasing intensity at increasing nominal gelatin content. It can be speculated that the spatial distribution of gelatin in the fibers was different depending on the gelatin concentration, which may be due to changed mixing behavior. This experiment furthermore showed that gelatin is not washed out on contact with water, i.e., that gelatin was stably incorporated into the formulation.

Thermal transitions and crystallinities of the core-shell fibers containing varying amounts of gelatin were characterized by DSC experiments (Table 4 and SI Figure S9). The glass transition was superimposed with changes in heat flow due to strong relaxation effects and can therefore only be estimated from the DSC data. The isotactic crystallites had slightly lower $T_{\mathrm{m}} \mathrm{s}$ than those determined for the gelatin free samples, which may suggest a small crystallite size. Stereocrystallites were present in all samples.

The core/shell coaxial nonwovens were characterized by DMTA (Table 4 and SI Figures S10-S17) to determine and compare their $T_{\mathrm{g}} \mathrm{s}$ and storage moduli at physiological conditions on samples swollen in water prior to the measurement. The $T_{\mathrm{g}}$ can in this method be determined either from a maximum of the $\tan \delta$ or the maximum of $E^{\prime \prime}$, giving slightly different values. The $T_{\mathrm{g}}$ ( $\max$ $E^{\prime \prime}$ ) of gelatin free core/shell fibers (SI Figure S10) was $60^{\circ} \mathrm{C}$, but the curve can also be interpreted as having two $T_{\mathrm{g}} \mathrm{s}\left(50\right.$ and $\left.60^{\circ} \mathrm{C}\right)$. Such behavior can be explained by a slow water uptake, and hence a system in which a part of the polymer is plasticized by water, while other parts have not taken up water, yet. It was shown that the presence of gelatin tended to reduce the $T_{\mathrm{g}}$, most clearly from the $E^{\prime \prime}{ }_{\max }$ values, but not by much (by $0-6^{\circ} \mathrm{C}$ ). The determination of $T_{\mathrm{g}}$ in the samples and attributing the $T_{\mathrm{g}}$ to, e.g., the mixed PLAgelatin phase is hampered by the fact that the sum of core and shell behavior is recorded. The overall determined gelatin content is furthermore quite low, such that no strong effect on the thermal transition was to be expected. Moreover, glass transition temperatures of gelatin highly depend on the thermal history, water content of the samples, and measuring conditions, and have been reported to be between $\sim 75$ [51] and $>200{ }^{\circ} \mathrm{C}$ [52].

The observed reduction of $T_{\mathrm{g}}$ upon adding gelatin is in accordance with the literature $[41,53]$. It is, however, not clear whether this observed reduction is actually due to a mixed amorphous phase and/or because of higher water uptake into the matrix. The increased water uptake, however, is the most likely explanation, and consistent with expectations stated in the introduction. A longer incubation in water prior to the DMTA measurements actually resulted in slightly higher observed $T_{\mathrm{g}} \mathrm{s}$, however. The observed storage modulus of the coaxial spun nonwovens under physiological conditions varied nonlinearly with the nominal gelatin content. In earlier reports, an increase of Young's modulus with increasing gelatin content in PLA/gelatin blends was observed [41, 53], which is consistent with the data in this study.

An annealing study of the gelatin-containing patches by WAXS (Fig. 6D) demonstrated that PLA HC and SC were observed also in the presence of gelatin. Therefore, gelatin incorporation does not negatively impact the structural function of the system.

\section{Conclusion}

Coaxial electrospinning of PLLA and PDLA leads to core-shell fibers, in which stereocomplexes can form at the interface of the two layers. Neither isotactic nor stereocomplexation occurs during the electrospinning process or the evaporation of the solvent, as these processes are fast and the polymers at room temperature are below their $T_{\mathrm{g}}$. Annealing at temperatures clearly above the $T_{\mathrm{g}}$ allowed crystallization to take place, and the process can therefore be externally controlled. At the beginning 
TABLE 4: Thermal transitions, crystallinities, and storage moduli of coaxial PLLA/PDLA nanofibers with varying nominal gelatin content in the shell determined by DSC or DMTA.

\begin{tabular}{|c|c|c|c|c|c|c|c|c|c|c|}
\hline Sample & $\begin{array}{c}\mathrm{T}_{\mathrm{g}}^{\mathrm{a}} \\
{\left[{ }^{\circ} \mathrm{C}\right]}\end{array}$ & $\begin{array}{l}\mathrm{T}_{\mathrm{m}, \mathrm{HC}} \\
{\left[{ }^{\circ} \mathrm{C}\right]}\end{array}$ & $\begin{array}{c}\Delta \mathrm{H}_{\mathrm{m}, \mathrm{HC}} \\
{\left[\mathrm{J} \cdot \mathrm{g}^{-1}\right]}\end{array}$ & $\begin{array}{c}\phi_{\mathrm{c}}, \\
\mathrm{HC} \\
{[\%]} \\
\end{array}$ & $\begin{array}{l}\mathrm{T}_{\mathrm{m}, \mathrm{SC}} \\
{\left[{ }^{\circ} \mathrm{C}\right]}\end{array}$ & $\begin{array}{c}\Delta \mathrm{H}_{\mathrm{m}}, \\
\mathrm{SC} \\
{\left[\mathrm{J} \cdot \mathrm{g}^{-1}\right]}\end{array}$ & $\begin{array}{c}\phi_{\mathrm{c}}, \\
\mathrm{SC} \\
{[\%]}\end{array}$ & $\begin{array}{c}\mathrm{T}_{\mathrm{g}}(\tan \\
\left.\delta_{\max }\right) \\
{\left[{ }^{\circ} \mathrm{C}\right]} \\
\end{array}$ & $\begin{array}{c}\mathrm{T}_{\mathrm{g}} \\
\left(\mathrm{E}^{\prime,}{ }_{\text {max }}\right) \\
{\left[{ }^{\circ} \mathrm{C}\right]}\end{array}$ & $\begin{array}{c}\mathrm{E}^{\prime} \\
{[\mathrm{MPa}]}\end{array}$ \\
\hline $\begin{array}{c}\text { Core/shell } \\
0 \mathrm{wt} \% \\
\text { Gelatin }\end{array}$ & \multicolumn{7}{|c|}{ See Table 1} & 64 & 60 & 173 \\
\hline $\begin{array}{c}\text { Core/shell } \\
6.9 \mathrm{wt} \% \\
\text { Gelatin }\end{array}$ & 70 & 171 & 24.3 & 36 & 225 & 33.6 & 24 & 73 & 60 & 130 \\
\hline $\begin{array}{c}\text { Core/shell } \\
13.5 \mathrm{wt} \% \\
\text { Gelatin }\end{array}$ & 70 & 172 & 22.4 & 36 & 225 & 38.3 & 29 & 64 & 57 & 189 \\
\hline $\begin{array}{c}\text { Core/shell } \\
19.8 \text { wt } \% \\
\text { Gelatin }\end{array}$ & 70 & 172 & 22.7 & 38 & 225 & 39.3 & 30 & 65 & 56 & 163 \\
\hline $\begin{array}{c}\text { Core } / \text { shell } \\
25.9 \text { wt } \% \\
\text { Gelatin } \\
\text { Core/shell }\end{array}$ & 70 & 172 & 28.2 & 44 & 226 & 26.6 & 21 & $\begin{array}{c}61 \\
\left(72^{b}\right. \\
\left.67^{c}\right)\end{array}$ & $\begin{array}{c}54 \\
\left(61^{\mathrm{b}}\right. \\
\left.58^{\mathrm{c}}\right)\end{array}$ & $\begin{array}{c}207 \\
\left(220^{\mathrm{b}},\right. \\
\left.207^{\mathrm{c}}\right)\end{array}$ \\
\hline $\begin{array}{c}37.5 \mathrm{wt} \% \\
\text { Gelatin }\end{array}$ & 70 & 171 & 27.7 & 49 & 224 & 31.6 & 27 & 64 & 54 & 198 \\
\hline
\end{tabular}

Light background: DSC, gray background: DMTA. DMTA experiments were performed on samples that were pre-equilibrated in water for 30 min. a: $\mathrm{T}_{\mathrm{g}}$ not clearly showing in the DSC curves because of relaxation effects. b: swollen overnight in the clamped state. c: swollen overnight without being clamped. E': storage modulus at $37^{\circ} \mathrm{C}$.

of the annealing process, stress relaxation also occurs. As the stereocomplexes seem to act as nucleation sites for homocrystallization, the processing putatively allowed for control of the spatial distribution of crystallites. The overall structure and thermomechanical treatment gave annealed fibers that have Young's moduli that are lower than that of as-spun fibers, and core-shell structures that are softer compared to the PDLA and PLLA systems, despite the core-shell structures having higher degrees of crystallinity. Melting transitions and crystallinities observed in DSC experiments are likely due to crystallization processes occurring during the DSC heating and do not represent the situation at room temperature. Overall, the mechanical properties of the investigated system are fitting to the requirement of materials used in regenerative therapies.

Gelatin can be incorporated by co-electrospinning in the shell. The presence of gelatin on the surface can be visualized through fluorescence by NHS-fluorescein coupling, which shows that the biopolymer is presented to the exterior environment and is not washed out by incubation in aqueous solution. The overall fiber morphology can therefore be understood as a semi-interpenetrating polymer network with physical netpoints (crystallites). The determination of the exact localization of gelatin in the fiber and gelatin quantification was challenging because of the overall low gelatin and distinctive element content. The presence of gelatin had only a small reducing effect on the $T_{\mathrm{g}}$, as determined by DMTA, while the storage modulus increased when gelatin was incorporated. PLA homo- and stereocrystallization was not inhibited by the presence of gelatin. This shows that the overall design concept of tailoring the mechanical properties of PLA-based nanofibers, the switchability of the mechanical properties, and the nanofiber biofunctionalization could be reached by effective architectural design of the fibers and processing, relying on polymers established in the clinic. In the future, the biological evaluation of the introduced system and exploration of potential clinical fields of application will be investigated.

\section{Materials and methods}

\section{Materials}

PLLA of high molar mass ("PURASORB PL 24", $\mathrm{M}_{n}=83 \mathrm{~kg} \cdot \mathrm{mol}^{-1}, \mathrm{M}_{w}=145 \mathrm{~kg} \cdot \mathrm{mol}^{-1}$ ) and PDLA ("PURASORB PD 24", $\mathrm{M}_{w}=147 \mathrm{~kg} \cdot \mathrm{mol}^{-1}$ ) were purchased from Corbion (Amsterdam, the Netherlands), and PLLA $\left(\mathrm{M}_{w}=27 \mathrm{~kg} \cdot \mathrm{mol}^{-1}\right)$ from Sigma-Aldrich (Munich, Germany). The stated molar masses were determined in house by multidetector gel 
permeation chromatography (GPC). Hexafluoroisopropanol (HFIP) was from abcr GmbH (Karlsruhe, Germany), NHS-fluorescein from Thermo Fisher Scientific (Schwerte, Germany), and gelatin (from porcine skin, 200 bloom, type A, low endotoxin content) from GELITA USA (Sergeant Bluff, IA, USA).

\section{Electrospinning}

The electrospinning setup (Linari Engineering, 56121 Pisa, Italy) included voltage supply, rotatory drum collector, and two syringe pumps. The electrospinning process was performed inside a transparent plastic chamber connected with a variable air supply for humidity control. Solutions of $5 \mathrm{wt} \%$ PDLA (or in some experiments, a specified mixture of PDLA and gelatin) in HFIP and $12 \mathrm{wt} \%$ of a 5:1 (w/w) mixture of high and low molar mass PLLA in the same solvent were prepared. All solutions were filtered over a glass fiber syringe filter with a pore size of $1 \mu \mathrm{m}$ before electrospinning. For the core-shell fibers, a coaxial needle module (Linari Engineering) was used, where the inner blunt tip needle was gauge 21 and the outer was gauge 15 . The distance from the needle tip to the collector was set to $25 \mathrm{~cm}$. The flow rate of solution supply during electrospinning was $2.12 \mathrm{~mL} / \mathrm{h}$ for the shell solution and $1.41 \mathrm{~mL} / \mathrm{h}$ for the core solution. A polypropylene film was wrapped over the horizontally moving rotatory drum collector for collecting the fiber mesh. The drum collector with a diameter of $2.5 \mathrm{~cm}$ was rotated at $10 \mathrm{rpm}$ and an applied voltage of $20 \mathrm{kV}$ was maintained during the course of electrospinning. In the case of the single layer PLLA or PDLA fibers, a gauge 19 blunt tip needle was used, a flowrate of $2.12 \mathrm{~mL} / \mathrm{h}$ was employed, and the applied voltage was 14-17 kV (PDLA) or 15-17 kV (PLLA).

A second series of electrospinning experiments was performed on a NEU-BM electrospinning instrument (Shenzhen Tongli Micro-nano Technology Co. Ltd., China). A coaxial needle (inner needle internal diameter (ID) $0.6 \mathrm{~mm}$, outer needle ID $0.8 \mathrm{~mm}$ ) was used to dispense the working fluids. The syringes were placed on separate pumps (TL-F6, Shenzhen Tongli Micro-nano Technology Co. Ltd., China) and connected to the spinneret with polytetrafluoroethylene tubing. Flow rates of $5 \mathrm{~mL} / \mathrm{h}$ and $4 \mathrm{~mL} / \mathrm{h}$ were used for the shell and core fluids respectively. The applied voltage was $20 \mathrm{kV}$ and the collection distance was set at $15 \mathrm{~cm}$. A collapsible rotating mandrel developed and provided by Statice SAS was used as the collector. An auxiliary electrode was placed $7 \mathrm{~cm}$ away from the mandrel, and supplied with a $-6 \mathrm{kV}$ voltage. The mandrel was set to spin at $1000 \mathrm{rpm}$. The spinneret and auxiliary electrode were aligned and simultaneously rastered along the long axis of the mandrel at a constant speed of $30 \mathrm{~mm} \cdot \mathrm{s}^{-1}$. The ambient temperature and relative humidity were recorded throughout the experiments and kept constant at $25^{\circ} \mathrm{C}$ and $25 \pm 5 \%$ respectively.
To prepare gelatin-loaded materials, gelatin was dissolved in formic acid to a concentration of $7 \% \mathrm{w} / \mathrm{v}$ and then aliquots of this solution were taken to make 5, 10, 15, 20 and $30 \mathrm{v} / \mathrm{v} \%$ solutions with the PDLA (5 wt\%) solution.

\section{Annealing}

Annealing was performed by heating the nonwoven fiber mesh typically to $100{ }^{\circ} \mathrm{C}$ for $2 \mathrm{~h}$ (Figs. 3 and 4, Tables 1 and 2). In further investigations, the annealing temperature or time were varied, with annealing at $100^{\circ} \mathrm{C}$ for $25 \mathrm{~min}-36 \mathrm{~h}$, or annealing for $1 \mathrm{~h}$ at $60-120^{\circ} \mathrm{C}$, as indicated in the description of individual experiments and display items.

\section{Electron microscopy}

The morphology, size, and size distribution of the scaffolds were characterized by SEM (Phenom G2 pro, L.O.T. - Oriel (Darmstadt, Germany) for patches without gelatin, or ZEISS SEM SUPRA 40 VP, Jena, Germany) after conductive coating with a thin gold layer ( $5 \mathrm{~nm}$, Phenom) or carbon (Zeiss). The obtained SEM images were analyzed using ImageJ, an image processing software (version 1.44; National Institutes of Health) or Photoshop (CS 6, Adobe). An energy-dispersive X-ray (EDX) detector was employed to map the distribution of elements $(\mathrm{O}, \mathrm{C}, \mathrm{N})$ in some samples. The quantifiable limit is $0.5 \mathrm{wt} \%$. Only one sample (nominally containing $37.5 \mathrm{wt} \%$ gelatin in the shell) was above this limit, so that the other values can be regarded as indicative only.

\section{Thermogravimetry}

TGA analysis experiments were performed on a Netzsch TGA Phoenix 204 (Netzsch, Selb, Germany) between $25^{\circ} \mathrm{C}$ and $600{ }^{\circ} \mathrm{C}$ in an $\mathrm{N}_{2}$ atmosphere with a constant heating rate of $10^{\circ} \mathrm{C} \cdot \mathrm{min}^{-1}$.

\section{Differential scanning calorimetry}

DSC experiments were carried out on a Netzsch DSC Phoenix 204 (Netzsch, Selb, Germany) to investigate the thermal properties of the prepared scaffolds. Experiments were conducted in the temperature range from $-100^{\circ} \mathrm{C}$ to $220^{\circ} \mathrm{C}$ or to $300^{\circ} \mathrm{C}$ with a constant heating and cooling rate of $10^{\circ} \mathrm{C} \cdot \mathrm{min}^{-1}$ and a waiting period of $2 \mathrm{~min}$ at the maximum and minimum temperature. Melting temperatures $\left(\mathrm{T}_{\mathrm{m}} \mathrm{s}\right)$ were determined from the first and second DSC heating run, while glass transition temperatures $\left(\mathrm{T}_{\mathrm{g}} \mathrm{s}\right)$ were obtained from the second heating run. The crystalline ratio $\left(\phi_{c}\right)$ of homo- and stereocrystallites was calculated from the melting enthalpy of the first heating run by Eqs. (1) and (2): 


$$
\begin{gathered}
\phi_{\mathrm{c}}^{\mathrm{HC}}=\Delta \mathrm{H}_{\mathrm{m}}^{1 \mathrm{st}} \cdot\left(93 \mathrm{~J} \mathrm{~g}^{-1}\right)^{-1} \\
\phi_{\mathrm{c}}^{\mathrm{SC}}=\Delta \mathrm{H}_{\mathrm{m}}^{2 \mathrm{nd}} \cdot\left(142 \mathrm{Jg}^{-1}\right)^{-1}
\end{gathered}
$$

where $\Delta \mathrm{H}_{\mathrm{m}}{ }^{1 \text { st }}$ is the apparent melting enthalpy of the homocrystallites and $\Delta \mathrm{H}_{\mathrm{m}}{ }^{2 \text { nd }}$ the apparent melting enthalpy of the stereocrystallites. 93 and $142 \mathrm{~J} \cdot \mathrm{g}^{-1}$ are the literature values for the melting enthalpy of $100 \%$ crystalline polylactide homocrystallites [54] and stereocrystallites [55]. For the evaluation of different annealing times and temperatures, DSC experiments were conducted using a Q2000 DSC (TA Instruments, New Castle, DE, USA). Samples were heated from 20 to $250^{\circ} \mathrm{C}$ at $10^{\circ} \mathrm{C} \cdot \mathrm{min}^{-1}$ under a $50 \mathrm{~mL} \cdot \mathrm{min}^{-1}$ flow of $\mathrm{N}_{2}$ gas. Data analysis was carried out using the TA Universal Analysis software. A 5\% error for the measured enthalpy, stemming from sample handling and spectra integration, and $\pm 1{ }^{\circ} \mathrm{C}$ for the peak position (as stated by the manufacturer) were considered for the measurements.

\section{Dynamic mechanical thermal analyses}

DMTA measurements at varied temperatures were conducted with a Gabo (Ahlden, Germany) Eplexor 25 N. All experiments were performed in temperature sweep mode with a constant heating rate of $1^{\circ} \mathrm{C} \cdot \mathrm{min}^{-1}$ and an oscillation frequency of $1 \mathrm{~Hz}$. Samples were investigated in a temperature interval from 7 to $80^{\circ} \mathrm{C}$. The samples were preswollen in water for 30 minutes. Temperature measurements were recorded with a manufacturer-determined accuracy of $\Delta \mathrm{T}=1^{\circ} \mathrm{C}$.

\section{Wide-angle $\mathrm{X}$-ray scattering}

WAXS measurements were performed on dry samples at ambient temperature using a D8 Discover diffractometer with a twodimensional Hi-Star-detector (105 $\mu \mathrm{m}$ pixel size; Bruker AXS, Karlsruhe, Germany) using X-rays with $0.154 \mathrm{~nm}$ wavelength. A three-pinhole collimator with an opening of $0.8 \mathrm{~mm}$ was used. The distance between sample and detector was $150 \mathrm{~mm}$, whereas the samples with a thickness of about $1 \mathrm{~mm}$ were illuminated for $2 \mathrm{~min}$ in transmission geometry. Peak position was determined with $\Delta \theta=0.1^{\circ}$ error originating from variations in sample thickness and position in the sample holder. The degree of crystallinity (DOC) of samples was quantified by comparing the integrated areas of crystalline $\left(\mathrm{A}_{\text {cryst }}\right)$ and amorphous $\left(\mathrm{A}_{\text {amorph }}\right)$ regions according to Eq. (3). The error of the integration was estimated to be $20 \%$.

$$
D O C=\frac{A_{\text {cryst }}}{A_{\text {cryst }}+A_{\text {amorph }}}
$$

A second set of WAXS experiments was performed in Bragg-Brentano geometry on a Miniflex 600 diffractometer (Rigaku, Tokyo, Japan). The instrument produces $\mathrm{Cu} \mathrm{Ka}$ radiation (1.5418 $\AA$ ) at $40 \mathrm{kV}$ and $15 \mathrm{~mA}$, and patterns were recorded in the $2 \theta$ range 3 to $45^{\circ}$ at a speed of $10^{\circ} \mathrm{min}^{-1}$.

\section{Tensile tests}

Test specimens with a thickness of approximately 50-100 $\mu \mathrm{m}$, a width of $10 \mathrm{~mm}$, and a length of $40 \mathrm{~mm}$ were utilized for evaluation of the fibrous meshes' mechanical properties. The tests were performed at a constant deformation rate of $5 \mathrm{~mm} \cdot \mathrm{min}^{-1}$ until breakage occurred, either at ambient temperature with a Zwick Z005 (Zwick GmbH, Ulm, Germany) or in a Zwick Z2.5 (Zwick GmbH, Ulm, Germany) equipped with a water tank and a thermostat at $37^{\circ} \mathrm{C}$. For each composition, 3-5 specimens were tested and the mean value \pm standard deviation are reported.

\section{Fluorescein coupling and fluorescence microscopy}

The test was performed according to [37]. $1 \mathrm{mg}$ NHS-fluorescein was dissolved in $100 \mu \mathrm{DMSO}$ and added to $4.9 \mathrm{~mL}$ of a $100 \mathrm{mM}$ sodium carbonate buffer $(\mathrm{pH}=8)$. This solution was filtered through a sterile syringe filter with $0.2 \mu \mathrm{m}$ pore size. $6 \mathrm{~mm}$ punched samples of the core-shell nanofiber patches with varying nominal gelatin content were incubated in $200 \mu \mathrm{L}$ of the NHSfluorescein solution for $1 \mathrm{~h}$ in a 48 -well plate, followed by washing (3x) with phosphate buffered saline (PBS) and incubation with PBS overnight. A laser scanning confocal microscope (LSM 780, Carl Zeiss, Jena, Germany) was used to observe the green fluorescence from fluorescein and autofluorescence from the fibers.

\section{Acknowledgments}

We thank Yvonne Pieper and Daniela Radzik for the EM studies of the gelatin-containing patches, and Statice SAS for providing the mandrel used in some of the electrospinning experiments.

\section{Funding}

Open Access funding enabled and organized by Projekt DEAL. This work was financially supported by the Helmholtz Association through program-oriented funding and has received funding from the European Union's Seventh Framework Programme for research, technological development and demonstration under Grant Agreement No. 604049.

\section{Data availability}

The datasets generated during and/or analyzed during the current study are available from the corresponding author on reasonable request. 


\section{Declarations}

Conflict of interest The authors declare no conflict of interest.

\section{Open Access}

This article is licensed under a Creative Commons Attribution 4.0 International License, which permits use, sharing, adaptation, distribution and reproduction in any medium or format, as long as you give appropriate credit to the original author(s) and the source, provide a link to the Creative Commons licence, and indicate if changes were made. The images or other third party material in this article are included in the article's Creative Commons licence, unless indicated otherwise in a credit line to the material. If material is not included in the article's Creative Commons licence and your intended use is not permitted by statutory regulation or exceeds the permitted use, you will need to obtain permission directly from the copyright holder. To view a copy of this licence, visit http://creativecommons.org/ licenses/by/4.0/.

\section{Supplementary Information}

The online version contains supplementary material available at https://doi.org/10.1557/s43578-021-00260-z.

\section{References}

1. J. Xue, T. Wu, Y. Dai, Y. Xia, Electrospinning and electrospun nanofibers: methods, materials, and applications. Chem. Rev. (Washington, DC, U. S.) 119(8), 5298 (2019)

2. P.S. Suja, C.R. Reshmi, P. Sagitha, A. Sujith, Electrospun nanofibrous membranes for water purification. Polym. Rev. (Philadelphia, PA, U. S.) 57(3), 467 (2017)

3. M. Zhu, J. Han, F. Wang, W. Shao, R. Xiong, Q. Zhang, H. Pan, Y. Yang, S.K. Samal, F. Zhang, C. Huang, Electrospun nanofibers membranes for effective air filtration. Macromol. Mater. Eng. 302(1), 1600353 (2017)

4. S. Chen, R. Li, X. Li, J. Xie, Electrospinning: an enabling nanotechnology platform for drug delivery and regenerative medicine. Adv. Drug Delivery Rev. 132, 188 (2018)

5. J. Kluin, H. Talacua, A.I.P.M. Smits, M.Y. Emmert, M.C.P. Brugmans, E.S. Fioretta, P.E. Dijkman, S.H.M. Soentjens, R. Duijvelshoff, S. Dekker, M.W.J.T. Janssen-van den Broek, V. Lintas, A. Vink, S.P. Hoerstrup, H.M. Janssen, P.Y.W. Dankers, F.P.T. Baaijens, C.V.C. Bouten, In situ heart valve tissue engineering using a bioresorbable elastomeric implant - From material design to 12 months follow-up in sheep. Biomaterials 125, 101 (2017)

6. F. Xu, Y. Fan, Electrostatic self-assemble modified electrospun poly-L-lactic acid/poly-vinylpyrrolidone composite polymer and its potential applications in small-diameter artificial blood vessels. J. Biomed. Nanotechnol. 16(1), 101 (2020)
7. M. Rychter, A. Baranowska-Korczyc, B. Milanowski, M. Jarek, B.M. Maciejewska, E.L. Coy, J. Lulek, Cilostazol-loaded poly( $\varepsilon$ caprolactone) electrospun drug delivery system for cardiovascular applications. Pharm. Res. 35(2), 1 (2018)

8. M. Norouzi, S.M. Boroujeni, N. Omidvarkordshouli, M. Soleimani, Advances in skin regeneration: application of electrospun scaffolds. Adv. Healthcare Mater. 4(8), 1114 (2015)

9. A.J. Engler, S. Sen, H.L. Sweeney, D.E. Discher, Matrix elasticity directs stem cell lineage specification. Cell 126(4), 677 (2006)

10. A.T. Neffe, B.F. Pierce, G. Tronci, N. Ma, E. Pittermann, T. Gebauer, O. Frank, M. Schossig, X. Xu, B.M. Willie, M. Forner, A. Ellinghaus, J. Lienau, G.N. Duda, A. Lendlein, One step creation of multifunctional 3D architectured hydrogels inducing bone regeneration. Adv. Mater. 27(10), 1738 (2015)

11. S.M. Kurtz, J.N. Devine, PEEK biomaterials in trauma, orthopedic, and spinal implants. Biomaterials 28(32), 4845 (2007)

12. S.-C. Wong, A. Baji, S. Leng, Effect of fiber diameter on tensile properties of electrospun poly ( $\varepsilon$-caprolactone). Polymer $49(21)$, 4713 (2008)

13. G. Mathew, J.P. Hong, J.M. Rhee, D.J. Leo, C. Nah, Preparation and anisotropic mechanical behavior of highly-oriented electrospun poly(butylene terephthalate) fibers. J. Appl. Polym. Sci. 101(3), 2017 (2006)

14. T. Sauter, K. Kratz, M. Heuchel, A. Lendlein, Fiber diameter as design parameter for tailoring the macroscopic shape-memory performance of electrospun meshes. Mater. Des. 202, 109546 (2021)

15. P. Chavoshnejad, M.J. Razavi, Effect of the interfiber bonding on the mechanical behavior of electrospun fibrous mats. Sci. Rep. 10(1), 7709 (2020)

16. Y. Jing, L. Zhang, R. Huang, D. Bai, H. Bai, Q. Zhang, Q. Fu, Ultrahigh-performance electrospun polylactide membranes with excellent oil/water separation ability via interfacial stereocomplex crystallization. J. Mater. Chem. A 5(37), 19729 (2017)

17. I.K. Kwon, S. Kidoaki, T. Matsuda, Electrospun nano-to microfiber fabrics made of biodegradable copolyesters: structural characteristics, mechanical properties and cell adhesion potential. Biomaterials 26(18), 3929 (2005)

18. Q. Zhang, T. Rudolph, A.J. Benitez, O.E. Gould, M. Behl, K. Kratz, A. Lendlein, Temperature-controlled reversible pore size change of electrospun fibrous shape-memory polymer actuator based meshes. Smart Mater. Struct. 28(5), 055037 (2019)

19. R.P. Brannigan, A.P. Dove, Synthesis, properties and biomedical applications of hydrolytically degradable materials based on aliphatic polyesters and polycarbonates. Biomater. Sci. 5(1), 9 (2017)

20. H. Tsuji, Y. Ikada, Blends of crystalline and amorphous poly(lactide). III. Hydrolysis of solution-cast blend films. J. Appl. Polym. Sci. 63(7), 855 (1997) 
21. A.M. Harris, E.C. Lee, Improving mechanical performance of injection molded PLA by controlling crystallinity. J. Appl. Polym. Sci. 107(4), 2246 (2008)

22. T. Chen, M. Xu, L. Zhao, L. Wang, Y. Qiu, Electrospun membranes of low molecular weight di-stereoblock poly (lactic acid) $s$ with high thermal stability and solvent resistance via low temperature sintering. J. Mater. Sci. 55(27), 13472 (2020)

23. V. Izraylit, M. Heuchel, O.E. Gould, K. Kratz, A. Lendlein, Strain recovery and stress relaxation behaviour of multiblock copolymer blends physically cross-linked with PLA stereocomplexation. Polymer. 209, 122984 (2020)

24. N.G.V. Fundador, A. Takemura, T. Iwata, Structural properties and enzymatic degradation behavior of PLLA and stereocomplexed PLA nanofibers. Macromol. Mater. Eng. 295(9), 865 (2010)

25. Q. Xie, X. Chang, Q. Qian, P. Pan, C.Y. Li, Structure and morphology of poly (lactic acid) stereocomplex nanofiber shish kebabs. ACS Macro Lett. 9(1), 103 (2020)

26. X. Zhang, R. Nakagawa, K.H.K. Chan, M. Kotaki, Mechanical property enhancement of polylactide nanofibers through optimization of molecular weight, electrospinning conditions, and stereocomplexation. Macromolecules 45(13), 5494 (2012)

27. H. Tsuji, M. Nakano, M. Hashimoto, K. Takashima, S. Katsura, A. Mizuno, Electrospinning of poly (lactic acid) stereocomplex nanofibers. Biomacromol 7(12), 3316 (2006)

28. D. Chuan, Y. Wang, R. Fan, L. Zhou, H. Chen, J. Xu, G. Guo, Fabrication and properties of a biomimetic dura matter substitute based on stereocomplex poly (lactic acid) nanofibers. Int. J. Nanomed. 15, 3729 (2020)

29. Y. Ren, L. Mei, Y. Gu, N. Zhao, Y. Wang, R. Fan, A. Tong, H. Chen, H. Yang, B. Han, Stereocomplex crystallite-based ecofriendly nanofiber membranes for removal of $\mathrm{Cr}$ (VI) and antibacterial effects. ACS Sustain. Chem. Eng. 7(19), 16072 (2019)

30. L. Mei, Y. Ren, Y. Gu, X. Li, C. Wang, Y. Du, R. Fan, X. Gao, H. Chen, A. Tong, Strengthened and thermally resistant poly (lactic acid)-based composite nanofibers prepared via easy stereocomplexation with antibacterial effects. ACS Appl. Mater. Interfaces. 10(49), 42992 (2018)

31. R. Lv, R. Tian, B. Na, P. Zhang, Q. Liu, Strong confinement effects on homocrystallization by stereocomplex crystals in electrospun polylactide fibers. J. Phys. Chem. B 119(50), 15530 (2015)

32. P. Zhang, R. Tian, B. Na, R. Lv, Q. Liu, Intermolecular ordering as the precursor for stereocomplex formation in the electrospun polylactide fibers. Polymer 60, 221 (2015)

33. H. Ajiro, S. Takahama, M. Mizukami, K. Kan, M. Akashi, K. Kurihara, Force estimation on the contact of poly(1, 1-lactide) and poly(d, d-lactide) surfaces regarding stereocomplex formation. Langmuir 32(37), 9501 (2016)

34. H. Tsuji, L. Bouapao, Stereocomplex formation between poly (L-lactic acid) and poly (D-lactic acid) with disproportionately low and high molecular weights from the melt. Polym. Int. 61(3), 442 (2012)

35. H. Kriel, R.D. Sanderson, E. Smit, Single polymer composite yarns and films prepared from heat bondable poly (lactic acid) core-shell fibres with submicron fibre diameters. Fibres Textiles Eastern Eur. 100(4), 44 (2013)

36. U. Hersel, C. Dahmen, H. Kessler, RGD modified polymers: biomaterials for stimulated cell adhesion and beyond. Biomaterials 24(24), 4385 (2003)

37. W.T. Tung, J. Zou, X. Sun, W. Wang, O.E. Gould, K. Kratz, N. Ma, A. Lendlein, Coaxial electrospinning of PEEU/gelatin to fiber meshes with enhanced mesenchymal stem cell attachment and proliferation. Clin. Hemorheol. Micro. 74(1), 53 (2020)

38. Z. Ma, W. He, T. Yong, S. Ramakrishna, Grafting of gelatin on electrospun poly (caprolactone) nanofibers to improve endothelial cell spreading and proliferation and to control cell orientation. Tissue Eng. 11(7-8), 1149 (2005)

39. V. Izraylit, P.J. Hommes-Schattmann, A.T. Neffe, O.E. Gould, A. Lendlein, Polyester urethane functionalizable through maleimide side-chains and cross-linkable by polylactide stereocomplexes. Eur. Polym. J. 137, 109916 (2020)

40. H.W. Kim, H.S. Yu, H.H. Lee, Nanofibrous matrices of poly(lactic acid) and gelatin polymeric blends for the improvement of cellular responses. J. Biomed. Mater. Res. Part A 87(1), 25 (2008)

41. S. Yan, L. Xiaoqiang, L. Shuiping, W. Hongsheng, H. Chuanglong, Fabrication and properties of PLLA-gelatin nanofibers by electrospinning. J. Appl. Polym. Sci. 117(1), 542 (2010)

42. D. Jia, Y. Gao, G.R. Williams, Core/shell poly (ethylene oxide)/ Eudragit fibers for site-specific release. Int J Pharmaceut. 523(1), 376 (2017)

43. O. Monticelli, M. Putti, L. Gardella, D. Cavallo, A. Basso, M. Prato, S. Nitti, New stereocomplex PLA-based fibers: effect of POSS on polymer functionalization and properties. Macromolecules 47(14), 4718 (2014)

44. V. Izraylit, O.E. Gould, T. Rudolph, K. Kratz, A. Lendlein, Controlling actuation performance in physically cross-linked polylactone blends using polylactide stereocomplexation. Biomacromol 21(2), 338-348 (2019)

45. A. Morel, S. Domaschke, V.U. Kumaran, D. Alexeev, A. Sadeghpour, S.N. Ramakrishna, S.J. Ferguson, R.M. Rossi, E. Mazza, A.E. Ehret, Correlating diameter, mechanical and structural properties of poly (L-lactide) fibres from needleless electrospinning. Acta Biomater. 81, 169 (2018)

46. H. Tsuji, Y. Ikada, Properties and morphologies of poly (L-lactide): 1. Annealing condition effects on properties and morphologies of poly (L-lactide). Polymer 36(14), 2709 (1995)

47. E. Lizundia, S. Petisco, J.-R. Sarasua, Phase-structure and mechanical properties of isothermally melt-and cold-crystallized poly (L-lactide). J. Mech. Behav. Biomed. Mater. 17, 242 (2013) 
48. R. Dersch, T. Liu, A. Schaper, A. Greiner, J. Wendorff, Electrospun nanofibers: Internal structure and intrinsic orientation. J. Polym. Sci. Part A 41(4), 545 (2003)

49. B. Dillon, P. Doran, E. Fuenmayor, A.V. Healy, N.M. Gately, I. Major, J.G. Lyons, Influence of annealing and biaxial expansion on the properties of poly (l-lactic acid) medical tubing. Polymers 11(7), 1172 (2019)

50. D. Cam, M. Marucci, Influence of residual monomers and metals on poly (L-lactide) thermal stability. Polymer 38(8), 1879 (1997)

51. I. Mukherjee, M. Rosolen, Thermal transitions of gelatin evaluated using DSC sample pans of various seal integrities. J. Therm. Anal. Calorim. 114(3), 1161 (2013)

52. P. Sobral, A. Habitante, Phase transitions of pigskin gelatin. Food Hydrocolloids 15(4-6), 377 (2001)
53. A.A. Leyva-Verduzco, M.M. Castillo-Ortega, L.H. Chan-Chan, E. Silva-Campa, R. Galaz-Méndez, R. Vera-Graziano, J.C. Encinas-Encinas, T. Del Castillo-Castro, D.E. Rodríguez-Félix, H. del Carmen Santacruz-Ortega, Electrospun tubes based on PLA, gelatin and genipin in different arrangements for blood vessel tissue engineering. Polym. Bull. 77, 5985-6003 (2019)

54. E. Fischer, H.J. Sterzel, G. Wegner, Investigation of the structure of solution grown crystals of lactide copolymers by means of chemical reactions. Kolloid Z. Z. Polym. 251(11), 980 (1973)

55. H. Tsuji, Poly (lactide) stereocomplexes: formation, structure, properties, degradation, and applications. Macromol. Biosci. 5(7), 569 (2005) 